period of growth. Conidiophores of $G$. Highlei are given off from the branch hyphæ after some four weeks in culture. As the effect of parasitism on the Nectria hyphæ is negligible, it is considered to be of a much controlled form.

(4) On extrast agars, intrahyphal growths occur within the lower conidiophore cells, and under natural conditions play a part in conidiophore proliferation.

Cniversity Department of Mycology, W. BLYTH Royal Botanic Garden, Edinburgh 4.

Feb. 15.

'Smith, A. L., and Rea, Carlton, Trans. Brit. Mycol. Soc., 3, 36 (1908). 'Ayers, T. T., Mycoldgia, 33, 178 (1941).

'Spaulding, P., J. Forestry, 46. 449 (1948).

\section{Death of Sycamore Trees Associated with an Unidentified Fungus}

AN unusual disease of sycamore (Acer pseudoplatanus L.) has been under observation in southwest Essex since autumn of $1945^{1}$. The disease, which is believed to be unrecorded hitherto, is associated with a peculiar unidentified fungus.

The first obvious symptoms are dark, vertical lesions on the trunk or branches, where the outer layer of bark has peeled off, exposing a mass of brownish-black powdery spores. Often large areas of apparently normal bark can be peeled off, exposing a thick layer of the spores, which have been produced from a stroma within the bark (see photograph). In later stages the tree is girdled and killed. When the bark has been shed, these dead trees are conspicuous by their dark, velvety appearance, and by the copious deposit of spores blackening the surrounding vegetation. The wood beneath young lesions is stained yellow-brown; but when the tree is dead the wood is light in colour and dry. Although proof of pathogenicity is as yet lacking, there is strong circumstantial evidence that the associated fungus is an active parasite, capable of attacking and killing sycamores of all ages.

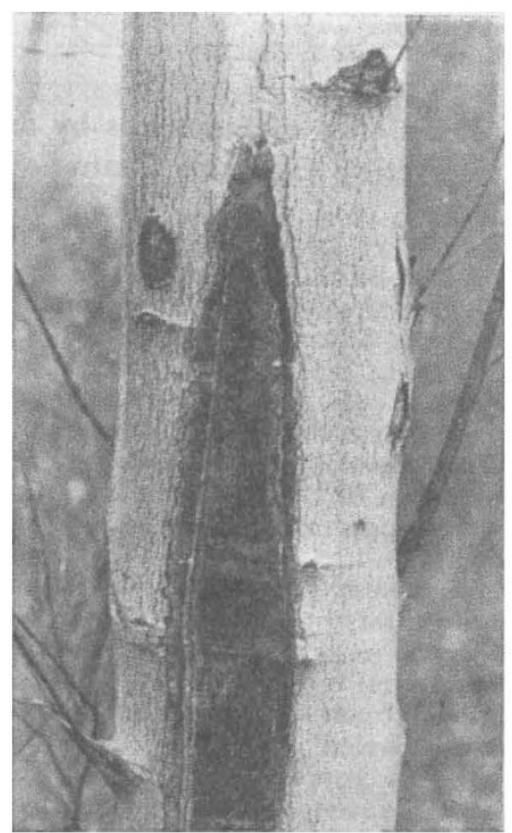

The staining travels up and down the trees, well beyond the external limits of the lesions and sometimes for the whole height of the trunk and main limbs. Most of the lesions appear to be formed at points where the staining extends to the cambium rather than by infection from without, and incipient lesions have been found where the cambium and inner bark were already dead, while the outer bark was still alive. The assumption is therefore that once the tree is infected the fungus travels up and down in the vessels, producing fresh lesions whenever it comes into contact with cambium. There is thus a strong resemblance between this disease and canker stain of plane trees (Plantanus) ${ }^{2}$ and sapstreak of sugar maple ${ }^{3}$ in the United States; both these diseases are associated with fungi of the genus Endoconidiophora.

With the sycamore disease, when the outer bark is peeled off, both the inner and outer portions are found to be covered by a thin plectenchymatous stroma. The inner stroma bears a closely packed hymenium of short phialides. The brown, unicellular, smooth, spherical-to-oval spores, $3 \mu \times 2 \mu$, are formed in fragile chains. The inner and outer stromatic layers are connected by plectenchymatous columns. These columns may be seen as a close layer of fine projections on the bark when the spores filling the interstices have blown away. Spore production is of the order of $10^{9}$ per sq. cm. The occurrence of other stages in the life-cycle of the fungus is suspected but not yet proved. The organism has been observed only on sycamore; but there has so far been no opportunity to examine other species of Acer or Platanus in the proximity of affected sycamores.

Investigation in the locality is being continued. The fungus appears to be a destructive parasite of the sycamore, and must be regarded as a pathogen of the first importance. From a single diseased tree seen in 1945 the disease has now spread over a mixed woodland area of about seventy acres, where more than a hundred sycamore trees are affected. As a precaution these have been felled and burned.

The object of this preliminary report is to stimulate search for this disease in other areas. We should be glad of further information on its distribution.

\section{P. H. GREGORY}

Rothamsted Experimental Station, Harpenden, Herts.

Forest Research Station,

T. R. Peace

Alice Holt Lodge,

Wrecclesham, Farnham, Surrey.

14 South Esk Road,

Forest Gate, London, E.7.

${ }^{1}$ Waller, S., Essex Naturalist, 28 (3) (in the press).

${ }^{2}$ Walter, J. M., U.S. Dept. Agriculture, Circular 742 (1946).

${ }^{3}$ Hepting, G. H., Phytopath., 24, 1069 (1944).

\section{Fluorescence of Soil Constituents in Ultra-violet Light}

THE only record of which I am aware of the use of the screened ultra-violet lamp for the detection of soil constituents is by H.L. Richardson". Richardson examined air-dried samples from a very comprehensive collection of soil profiles. He noted that soils rich in organic matter displayed a uniform coffeebrown or even blackish colour. A distinct fluorescence 